\title{
The Impact of Trade Liberalization on the Manufacturing Sector in Jordan
}

\author{
Mohammed Alawin ${ }^{1,2}$, Bader Obeidat ${ }^{3}$, Muawiya Attiyat ${ }^{1}$, Buthaina Muhtaseb ${ }^{1}$, Ghazi Al-Assaf ${ }^{1}$ \& Alaaeddin \\ Al-Tarawneh ${ }^{1}$ \\ ${ }^{1}$ Economics Department, the University of Jordan, Amman, Jordan \\ ${ }^{2}$ Economics Department, Kuwait University, Kuwait \\ ${ }^{3}$ Department of Business Management, the University of Jordan, Amman, Jordan \\ Correspondence: Mohammed Alawin, Department of Economics, The University of Jordan, Amman, Jordan. \\ E-mail: m_alawin@hotmail.com
}

Received: September 22, 2016

Accepted: November 11, 2016 Online Published: February 3, 2017

doi:10.5539/jsd.v10n1p34

URL: http://dx.doi.org/10.5539/jsd.v10n1p34

\begin{abstract}
This study examines the impact of the degree of trade openness, real exchange rate $(R E R)$ and the level of imports on the production of the manufacturing sector in Jordan for the monthly period (1992-2012). This study applies the Chow test for structural changes. The results show that the year 2000, when Jordan officially joined the World Trade Organization (WTO), represents a year of structural change. Thus, the study has divided the full period into two sub-periods. In addition, the results of the study indicate the absence of a cointegration relationship over the period leading up to Jordan's accession to the WTO. The period that follows the trade openness has shown the presence of cointegration and long-term relationship among the variables. Specifically, for the second period, the study found that the degree of trade openness has a positive and a statistically significant effect on the manufacturing production. Therefore, the study recommends that the government continue to support the manufacturing sector and not to raise any input costs on it, especially given the relatively high cost of fuel and electricity. This should keep the competitiveness of this sector relatively high.
\end{abstract}

Keywords: trade liberalization, manufacturing sector, WTO, ARDL, Jordan

\section{Introduction}

The manufacturing sector in developing countries plays a minor role in the process of economic growth. In fact, we find that the economies of developing countries are controlled, mostly, by agriculture and services sectors. The manufacturing sector is still suffering from a decline in the value added as well as problems relating to competitiveness, quality and commitment to standards and metrology (Kawaz, 2012). In Jordan, the weak role of the manufacturing sector coincides with Jordan's decision for implementing procedures that seek more of trade openness and liberalization. Among these measures is joining the World Trade Organization (WTO) and strengthening trade relations with Arab and foreign countries through signing a number of trade agreements, such as: the Convention of the Greater Arab Free Trade, the agreement of partnership with the European Union, the agreements of free trade and the Qualified Industrial Zones (QIZ) with the United States, the free trade agreements with EFTA, Singapore, Canada and Turkey.

The main aim of this study is to estimate the impact of the openness to trade in the manufacturing sector on the performance of the manufacturing sector in Jordan. The analyses of this study involve quarterly data for the time period (1992-2012). This will be done through applying an econometric model that helps giving clear outcome on the issue of the impact of trade openness on the Jordanian economy. The rest of this paper is organized as follows: Section 2 provides the literature review. Section 3 gives a brief look at the development of the Jordanian economy. Section 4 gives discussions of the empirical methodology. Section 5 presents the empirical results. Finally, Section 6 concludes the study.

\section{Literature Review}

Previous studies on the subject of trade openness and its impact on the manufacturing sector on the local level, according to best of the researchers' knowledge, are rare. In addition, we find that most studies have linked trade liberalization with other economic variables like real GDP, macroeconomic policies and the balance of payments. 
However, these studies characterized with differences in their empirical results and conclusions.

Locally, Amr (2012) analyzed the impact of trade openness on value added, profit margins, productivity, and trade balance. The results showed a decline in the index in both profit margin ratio and the trade balance, and improving in both the productivity and the value added. Nsour (2009) analyzed the impact of trade openness on the pharmaceutical industry in Jordan. He addressed cross sectional data for a number of Jordanian pharmaceutical companies during the year 2008. The results of this study proved a positive and statistically significant relationship between the pharmaceutical production industry and trade openness.

At the international level, Hathaway (2007) has analyzed the effect of free trade on the industrial sector in the United States for the period (1970-2000). The results of this study showed a positive impact of trade openness on the industrial sector. This is attributed to the competitive advantages, the existence of more markets to sell products, and lower costs of production. However, Goldar \& Aggarwal (2005) confirmed the same result for the Indian industry for the period (1980-1997). The same result was reached also by Mouelhi (2007), which dealt with the impact of trade liberalization on the manufacturing industry in Tunisia for the period (1987-1995). It was concluded that there is a positive impact, but this relationship was statistically insignificant.

\section{Jordanian Economy in Brief}

The Jordanian economy depends heavily on many factors. Most importantly (as is the case in the year 2012): external grants ( $5 \%$ of GDP), workers' remittances ( $10 \%$ of GDP), flows of Arab and foreign investments ( $3 \%$ of GDP), and tourism receipts ( $10 \%$ of GDP). In addition, the outcome of phosphate and potash exports, clothing, and vegetables are equivalent to $22 \%$ of GDP (the Department of Statistics, 2013).

Regarding the development of foreign trade, domestic exports reached a value of 4.8 billion dinars in 2012 while the value of imports rose during the same year to $\$ 14.7$ billion dinars. The ratio of deficit in trade balance to GDP was $37.9 \%$ of GDP in 2012, compared to a deficit ratio of $41.4 \%$ in 2011.

International trade partners are represented, mainly, in the Greater Arab Free Trade Area which includes mainly Iraq and Saudi Arabia, the Free Trade Agreement (NAFTA) of the North American which includes the United States, non-Arab Asian countries including India and China, and the European Union countries including Germany in particular.

The contribution of the manufacturing sector in GDP at the end of 2012 was $20 \%$. The total value added of the manufacturing sector reached 1JD billion at current prices for the year 2012. The production quantities index of the manufacturing industry increased by $15 \%$ in 2012 compared to 2011. There is no doubt that the manufacturing industry in Jordan has experienced a good growth, however, a large part of this growth is due to the rise in the prices of the products of manufacturing sector (Central Bank of Jordan, 2013).

It is expects for the Jordanian economy, as an growing economy, to have an annual growth rate in its industrial production sector not less than 5\%, which is the expected rate of growth of the Jordanian economy in this period. But official statistics says that the economy rose only by $1.3 \%$ for the first quarter of 2013 , meaning that there is an industrial problem hinders the planned growth. If we take into account the importance of the industrial sector, having the highest contribution to GDP, the consideration of the problem and treatment becomes an urgent need.

\section{Methodology}

The methodology of this study is based on using an econometric model includes trade openness (the independent variable) and its impact on the manufacturing sector of Jordan (the dependent variable). The study model contains other independent variables; the real exchange rate $(R E R)$ and imports. The study collects data from the bulletins of the Central Bank of Jordan and the Department of Statistics for the quarterly period (1992:1-2012:4).

This study uses the following econometric model in order to determine the effect of trade openness on the performance of the manufacturing sector. This model is based on the economic theories and industrial issues facing the Jordanian economy:

$$
\ln Y_{t}=a_{0}+a_{1} T O_{t}+a_{2} R_{E R}+a_{3} \operatorname{LnIM}_{t}+e_{t}
$$

where $\ln Y$ is the natural logarithm of the value of production in the manufacturing sector, LnIM is the natural logarithm of imports, $a_{0}$ is the intercept, $a_{i}$ is the unknown parameters (where $i=1,2$, and 3 ), $e$ is the error term, $t$ is time period and $T O$ represents trade openness and will be calculated as follows:

$$
T O=(E X+I M) / G D P
$$

where $E X$ is exports, $I M$ is imports, and GDP is Gross Domestic Product. Finally, RER is the Real Exchange Rate and it is measured as follows: 


$$
R E R=E *\left(C P I_{J} / C P I_{U S}\right)
$$

where $E$ is the nominal exchange rate (number of dollars per one dinar), $C P I_{J}$ and $C P I_{U S}$ are the Consumer Price Index in Jordan and the U.S., respectively.

This study is based, in its methodology, on analyzing the time series for the variables of the study through applying the following tests: Stationary test, Chow test for structural break, Cointegration test using Autoregressive Distributed Lag $(A R D L)$, Error Correction Mechanism $(E C M)$, and Granger Causality test.

\section{Empirical Results}

The economic model of this study deals with the relationship between trade openness and manufacturing production. According to economic theory, trade openness will lead to an increase in the industrial production if some conditions are met, like: the availability of perfect competition, absence of monopoly, availability of full information and producing at the same cost (Awad, 2000).

In order to analyze the relationship between the variables of the model for the impact of economic openness on industrial production, the first steps that should be done is to know whether there would exist a structural change in the time-series data, especially in 2000; the year of Jordan's accession to the WTO. The null hypothesis has been tested of no structural change versus the alternative one of the existence of a structural change. The results showed that the null hypothesis was rejected at $1 \%$ level of significance. This suggests the need to separate the full period into two sub-periods; before and after accession the WTO. The first sub-period covers time period (1992:1-1999:4) while the second sub-period covers the time period (2000:1-2012:4).

\subsection{The Pre-Open Trade Period}

\subsubsection{Stationarity Test}

In order to analyze the relationship between the variables in the period prior to the openness of trade, variables should be tested first for stationarity (whether a unit root exists or not). Table (1) summarizes the results of the stationarity test of the variables to the pre-opening trade period (1992:1-1999:4). The test results were reported according to the Augmented Dickey Fuller (ADF) test.

Table 1. The results of the ADF test for the variables model (The first period)

\begin{tabular}{|c|c|c|c|c|}
\hline \multicolumn{5}{|c|}{ ADF Results Using the Intercept Alone } \\
\hline Variables & Level & & First Difference & \\
\hline $\operatorname{Ln} Y$ & -4.685 & * & -6.469 & $*$ \\
\hline TO & -2.505 & & -10.790 & * \\
\hline$R E R$ & -1.944 & & -5.303 & $*$ \\
\hline LnIM & -1.773 & & -7.743 & \\
\hline
\end{tabular}

\begin{tabular}{|c|c|c|c|c|}
\hline \multicolumn{5}{|c|}{ ADF Results Using both the Intercept and the Trend } \\
\hline Variables & Level & & First Difference & \\
\hline $\operatorname{Ln} Y$ & -6.798 & $*$ & -6.355 & * \\
\hline TO & -2.387 & & -10.69 & $*$ \\
\hline$R E R$ & -3.877 & $*$ & -3.805 & $*$ \\
\hline LnIM & -4.784 & & -7.956 & $*$ \\
\hline
\end{tabular}

Note. $*$ indicates rejection of null hypothesis (non-stationarity of the variable) at $1 \%$ significant level.

The results showed that production variable $(\ln Y)$ for the pre-opening trade was stationary at the level, that is, it is integrated of order 1 ; $\mathrm{I}(0)$. RER becomes stationary when using intercept and trend in the unit root equation, meaning it is also integrated of order zero (at 1\% level of significance). Both trade openness (TO) and imports $(L n I M)$ become stationary when taking the first difference, which means that they integrated of order $1 ; \mathrm{I}(1)$.

\subsubsection{Cointegration Test}

Since the variables of the model were not all integrated of the same order and became stationary (and integrated) of different orders, there is still a possibility to detect the presence of cointegration (a long-term relationship) 
among variables. To detect the presence of this relationship (under the stationarity of the variables at different levels), the Autoregressive Distributed Lag ( $A R D L)$ will be utilized, which was proposed by Pesaran, et al (2001), according to the following formula:

$$
\begin{aligned}
& \Delta \operatorname{Ln} Y_{t}=B_{0}+\sum_{i=1}^{p} \alpha_{i} \Delta \operatorname{Ln} Y_{t-i}+\sum_{j=0}^{q} \alpha_{j} \Delta T O_{t-j}+\sum_{k=0}^{r} \alpha_{k} \Delta R E R_{t-k}+\sum_{w=0}^{s} \alpha_{w} \Delta \operatorname{lnI} M_{t-w}+B_{1} \operatorname{Ln} Y_{t-1}+ \\
& B_{2} T O_{t-1}+B_{3} R E R_{t-1}+B_{4} L n I M_{t-1}+\epsilon_{t}
\end{aligned}
$$

The ARDL equation consists of two parts: parameters for variables of first difference format $\left(\alpha_{i}, \alpha_{j}, \alpha_{k}\right.$, and $\left.\alpha_{w}\right)$ and parameters for variables of level format but one period lag $\left(B_{1}, B_{2}, B_{3}\right.$, and $\left.B_{4}\right)$. ( $\left.\Delta\right)$ refers to the first difference of the variables, while $B_{0}$ indicates the intercept. The $(p, q, r$, and $s)$ refer to the lags periods for the variables of the first difference and $\epsilon$ refers to the error term.

In order to perform the cointegration test among the variables in this model for Equation (2), we formulated the following hypotheses:

Null hypothesis: no cointegration among variables $\left(H_{0}: B_{1}=B_{2}=B_{3}=B_{4}=0\right)$.

Alternative hypothesis: cointegration among variables does exist $\left(H_{1}: B_{1} \neq B_{2} \neq B_{3} \neq B_{4} \neq 0\right)$.

After estimating the cointegration model according to Schwarz Bayesian Criterion $(S B C)$, the results of the cointegration test appears in Table (2) as follows:

Table 2. The results of cointegration test (The period precedes trade openness)

\begin{tabular}{ccc}
\hline The function: & Wald test \\
$\operatorname{Ln} Y=F(T O, R E R, \operatorname{LnIM})$ & \multicolumn{2}{c}{ F-statistic=2.736[0.06] } \\
\hline & \multicolumn{2}{c}{ Critical values bunds } \\
Significant level & Lower critical Bounds & Upper critical bounds \\
\hline $1 \%$ & 4.29 & 5.61 \\
$5 \%$ & 3.79 & 4.85 \\
\hline
\end{tabular}

To verify the existence of cointegration between the variables in the model for the period preceding the trade openness (1992:1-1999:4), the value of the F-statistic has been obtained, which equals to 2.736; a value that is less than the lower critical bound (LCB) in the table that provides the maximum and the minimum statistical values specified for this test. This means there is no cointegration between the variables in this period. In other words, there is an absence of a long-term relationship among the variables in the period preceding the trade openness.

\subsection{The Period after Trade Openness}

\subsubsection{Stationarity Test}

The results of the stationarity test, using the ADF test, for the variables of the study for the period that follows the trade openness shows that the production variable $(\ln Y)$ is stationary only at the difference or it was integrated of order 1; I(1). The same results were obtained for RER and the degree of trade openness (TO). Imports (LnIM) have become stationary when using a trend and an intercept. Table (3) summarizes the results of the ADF test for the model's variables for the period following trade openness (2000:1-2012:4).

Table 3. The results of the ADF test for the variables of the model (The second period)

\begin{tabular}{lccc}
\hline \multicolumn{4}{c}{ ADF Results Using the Intercept Alone } \\
\hline Variables & Level & First Difference & $*$ \\
\hline LnY & -2.765 & -9.303 & $*$ \\
TO & -1.302 & -4.088 & $*$ \\
RER & 1.234 & -4.800 & $*$ \\
LnIM & -1.575 & -7.589 & \\
\hline
\end{tabular}




\begin{tabular}{lccc}
\hline \multicolumn{4}{c}{ ADF Results Using both the Intercept and the Trend } \\
\hline Variables & Level & First Difference & $*$ \\
\hline LnY & -2.647 & -9.372 & $*$ \\
TO & -3.110 & -4.035 & $*$ \\
RER & -2.1708 & -5.139 & $*$ \\
LnIM & -2.663 & -7.480 & $*$ \\
\hline Note. ${ }^{*}$ indicates rejection of null hypothesis (non-stationarity of the variable) at $1 \%$ significant level.
\end{tabular}

\subsubsection{Cointegration Test}

The cointegration model was estimated for the study's model according to Equation (2), for the period (2000:1-2012:4), based on ARDL method. Table (4) shows the results of this test:

Table 4. The results of cointegration test (The second period)

\begin{tabular}{ccc} 
The function: & \multicolumn{2}{c}{ Wald test } \\
$\operatorname{Ln} Y=F(T O, R E R, L n I M)$ & \multicolumn{2}{c}{ F-statistic=5.654 [.001] } \\
\hline & \multicolumn{2}{c}{ Critical values bunds } \\
Significant level & Lower critical Bounds & Upper critical bounds \\
\hline $1 \%$ & 4.29 & 5.61 \\
$5 \%$ & 3.79 & 4.85 \\
\hline
\end{tabular}

To verify the existence of cointegration among the variables in the model for the period that followed the opening trade, we obtained the F-statistic value which equal to 5.654. This value is higher than the upper critical bound (UCB) in the table that provides the maximum and the minimum statistical values specified for this test. This result confirms the existence of a cointegration (long-term relationship) between the variables in the period that followed Jordan's accession to the WTO.

Due to the existence of a cointegration between the variables of the model, after the implementation of the ADF test, the cointegration result involves a long-term relationship that takes the following formula (where numbers inside parentheses are t-statistic):

$$
\begin{gathered}
\operatorname{Ln} Y=3.351+0.274 \text { TO }-6.833 \text { RER }-0.610 \text { LnIM } \\
{[0.011] \quad[0.004] \quad[-0.000] \quad[-0.023]}
\end{gathered}
$$

It appears from Equation (3) that the TO coefficient has a positive sign. This indicates a higher degree of trade openness will lead to increases in production of the manufacturing sector. The reason for this is attributed to the presence of new markets and new consumers who allow producing (and exporting) more to them. Trade openness, through increasing competition and opening new markets, works to reduce production costs. These arguments are consistent with Kawaz (2012) and Nsour (2009), while this result contradicts the finding of Mouelhi (2007) and Amr (2012).

As for imports $(\operatorname{LnIM})$, it has a negative effect on the production of the manufacturing sector and this is consistent with Hindawi (2003), due to the inability of local companies to compete with foreign ones since most of Jordan's imports are for consumption purposes (Kawaz, 2012).

\subsection{Error Correction Mechanism (ECM) For the Period after Opening Trade}

The term of the error correction is included in models that show cointegration among their variables. Depending on the statistical significance of the coefficient of error correction term $(\gamma)$, the nature of the long-term causal relationship between variables will be determined. ECM is written according to the following formula (Engle \& Granger, 1987):

$$
\begin{gathered}
\Delta \operatorname{Ln} Y_{t}=c+\sum_{i=0}^{p} \alpha_{i} \Delta \operatorname{Ln} Y_{t-i}+\sum_{j=0}^{q} \alpha_{j} \Delta T O_{t-j}+\sum_{k=0}^{r} \alpha_{k} \Delta R E R_{t-k}+\sum_{w=0}^{s} \alpha_{w} \Delta \ln I M_{t-w}+ \\
\gamma E C T_{t-1}+\varepsilon_{t}
\end{gathered}
$$


where $\gamma$ is the coefficient of error correction term, $E C T_{t-1}$ is the error correction term for the previous period, which is obtained from a long-term relationship of the production model, $\varepsilon_{t}$ is error term.

The production model for the period that followed the trade openness contains cointegrated variables. The direction of causality in Equation (4), in the long term, is determined through the statistical significance of the coefficient of the error correction term. If this parameter is statistically significant, it indicates the existence of a causal relationship between the independent variables and the dependent variable in the period following the opening of trade. After estimating Equation (4), the results of estimating the ECM appear as follows (where numbers inside parentheses are t-statistic):

$$
\begin{aligned}
& \Delta \ln Y_{t}=0.0146+0.0945 \Delta \ln Y_{t-1}-0.1133 \Delta \ln Y_{t-2}+0.2616 \Delta T O_{t-1}+0.367 \Delta T O_{t-2} \\
& {[0.91] \quad[0.3747] \quad[-0.56] \quad[1.41] \quad[2.00]} \\
& -2.570 \Delta R E R_{t-1}-4.5459 \Delta R E R_{t-2}-0.33 \Delta L_{n I M} M_{t-1}-0.59 \Delta \operatorname{LnIM}_{t-2}-0.69 E C T_{t-1} \\
& {[-0.252] \quad[-0.4391] \quad[-1.068] \quad[-2.226] \quad[-2.51]}
\end{aligned}
$$

Regarding the coefficient of the error correction term $(\gamma)$, it has a value of (-0.69). It has the expected sign and it was statistically significant, which confirms the existence of a long-term relationship between the variables for the period that following Jordan's accession to the WTO. This reflects the speed of adjustment for a shock experienced by the independent variables affecting the dependent variable and to be adjusted by $69 \%$ in the subsequent periods.

\subsection{Causality Test}

Figure (1) shows the results and the directions of causality after implementing the Granger Causality test which contains the causality in the short term. The results show that imports cause changes in the degree of trade openness. In addition, there is also a causal correlation between $R E R$ and imports.

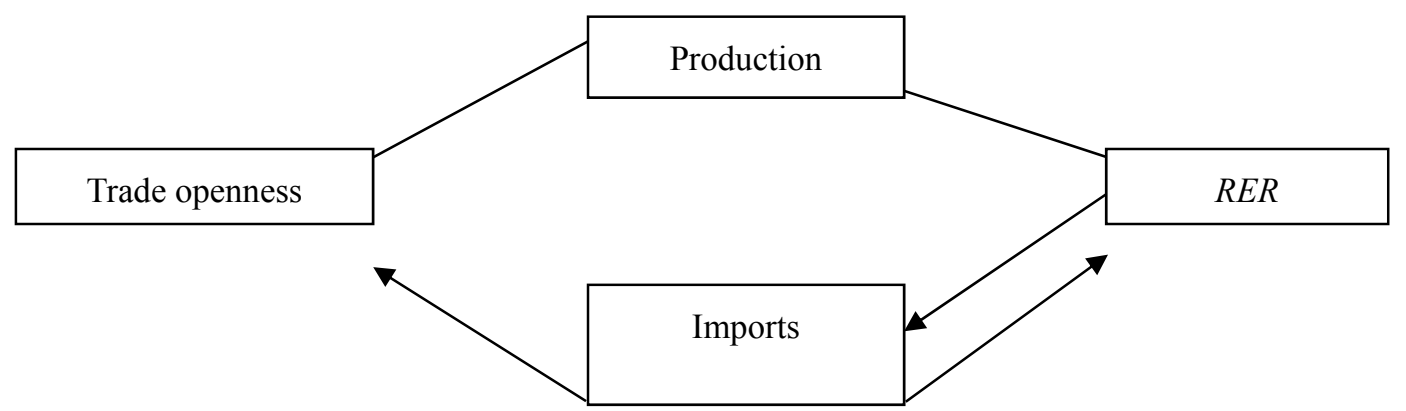

Figure 1. Granger causality results for the period following trade openness

\section{Conclusion}

The objective of this study is to figure out the nature of the relationship between trade openness and the performance of the manufacturing sector in Jordan during the period (1992-2012) through utilizing a set of econometric tests. The results of this study showed through testing for structural changes that year 2000, in which Jordan joined the WTO, is the year of structural changes. Therefore, the study considered the year 2000 is the real beginning of the phase of economic openness for Jordan. When testing ARDL for cointegration for the period that preceded the trade openness, the results show the lack of a long-term relationship between the independent variables and the dependent variable. However, the results showed the existence of cointegration between the variables for the period that followed the opening up of trade. In this case, we find an indication to the existence of a long-term relationship between the degree of openness to trade, $R E R$, and imports from one side and the manufacturing sector from another side. The results showed that the effect of the degree of trade openness on production was positive and is statistically significant. However, the impact of RER and imports are negative.

Therefore, this study recommends reviewing the state of the manufacturing sector and not to raise input costs on it, given the relatively high cost of fuel, electricity and wages. Needless to say, this sector is getting exposure to unfair competition from the main foreign trade partners. Accordingly, Jordan should accept trade agreements that take into account the situation of the Jordanian economy. 


\section{References}

Amr, H. (2012). The Effect of Trade Openness on the Competitiveness of the Manufacturing Sector in Jordan (Unpublished doctoral dissertation). The University of Jordan, Amman, Jordan.

Awad, T. (2000). International Trade (2nd ed.). Amman, Jordan, Institute of Banking Studies.

Central Bank of Jordan. (2013). Monthly Statistical Bulletin. Amman, Jordan, Central Bank of Jordan.

Department of Statistics. (2013). monthly bulletins. Amman, Jordan, Department of Statistics.

Engle, R,. \& Granger, C. (1987). Cointegration and Error Correction: Representation, Estimation and Testing. Econometrica, 55(2), 251-276. http://dx.doi.org/10.2307/1913236

Goldar, B., \& Aggarwal, C. (2005). Trade Liberalization and Price-Cost Margin in Indian Industries. Journal of The Developing Economies, 43(3), 346-73. http://dx.doi.org/10.1111/j.1746-1049

Hathaway, O. (2007). Positive Feedback: The Impact of Trade Liberalization on Industry. Journal of International Organization, 3(52), 575-612.

Kawaz, A. (2012). Industrial Policies and Globalization (1st ed.). Kuwait, Arab Planning Institute.

Mouelhi, R. (2007). The Impact of Trade Liberalization on Tunisian Manufacturing: Structure, Performance and Employment. Region et Developpement, 14, 87-114.

Nsour, A. (2009). The competitive Performance of the Jordanian pharmaceutical Industry Companies in Light of Economic Openness (Unpublished doctoral dissertation). University of Tishrin, Damascus, Syria.

Pesaran M., Shin, Y., \& Smith R. (2001). Bounds Testing Approaches to the Analysis of Level Relationships. Journal of Applied Econometrics, 16(3), 289-326. http://dx.doi.org/10.1002/jae.616

\section{Copyrights}

Copyright for this article is retained by the author(s), with first publication rights granted to the journal.

This is an open-access article distributed under the terms and conditions of the Creative Commons Attribution license (http://creativecommons.org/licenses/by/4.0/). 